\title{
The expression and prognostic impact of CXC-chemokines in stage II and III colorectal cancer epithelial and stromal tissue
}

\section{O Oladipo', S Conlon², A O'Grady', C Purcell', C Wilson', PJ Maxwell', PG Johnston', M Stevenson ${ }^{3}$, EW Kay², RH Wilson' and DJJ Waugh",I}

'Centre for Cancer Research and Cell Biology, Queen's University Belfast, 97 Lisburn Road, Belfast BT9 7BL, Northem Ireland; ${ }^{2}$ Department of Histopathology, Royal College of Surgeons in Ireland, Beaumont Hospital, Dublin, Ireland; ${ }^{3}$ Centre for Public Health, Queen's University Belfast, Belfast BT9 7BL, Northern Ireland

BACKGROUND: The CXC-chemokine expression is linked with colorectal cancer (CRC) progression but their significance in resected CRC is unclear. We explored the prognostic impact of such expression in stage II and III CRC.

METHODS: Tissue microarrays were constructed from stage II and III CRC biopsies $(n=254)$, and the expression of CXCLI and CXCL8, and their receptors CXCRI and CXCR2, in malignant and adjacent normal tissue was graded by immunohistochemistry and was correlated with prognostic factors.

RESULTS: Expression of CXCLI, CXCRI and CXCR2 was elevated in tumour epithelium relative to normal adjacent tissue $(P<0.00 \mathrm{I})$. CXCL8 expression was detectable in the peritumoural inflammatory infiltrate. There was no overall association between CXCLI, CXCRI or CXCR2 expression and prognostic endpoints; however, univariate subgroup survival analysis demonstrated an inverse association between CXCLI and recurrence-free survival (RFS) in stage III patients $(P=0.04 \mathrm{I})$. The CXCL8 positivity in the tumour infiltrate, however, correlated with earlier disease stage $(P<0.00 \mathrm{I})$ and improved relapse-free survival across the cohort $(P<0.00 \mathrm{I})$. Disease stage $(P<0.00 I)$ and tumour infiltrate CXCL8 positivity $(P=0.007)$ were associated with enhanced RFS in multivariate Cox regression analysis.

CONCLUSION: Autocrine CXC-chemokine signalling may have adverse prognostic effects in early CRC. Conversely, CXCL8 positivity within the immune infiltrate may have good prognostic significance.

British Journal of Cancer (20II) I 04, 480-487. doi:I0.1038/sj.bjc.6606055 www.bjcancer.com

(C) 20II Cancer Research UK

Keywords: CXCLI; CXCL8; CXCRI; CXCR2; colorectal cancer

Colorectal cancer (CRC) remains a major cause of morbidity and mortality in the Western world, accounting for more than one in eight newly diagnosed cancers in Europe and over half a million deaths worldwide annually (Parkin et al, 2005; Ferlay et al, 2007). Despite this, only half of the patients who undergo potentially curative surgery survive for 5 years (McArdle and Hole, 2002), and the challenge of how best to predict prognosis and, thereby optimise therapy remains. At present, established clinico-pathological criteria are used to estimate risks of recurrence in stage II and III disease, and this is routinely used in the selection of patients for adjuvant systemic therapy following surgical resection. The clinical outcome of patients who receive such adjuvant treatment can, however, vary widely, when additional molecular factors are taken into consideration (Allegra et al, 2003). Identification of novel prognostic markers is, therefore, vital in improving the prognosis of this disease.

Chemokines are a large family of chemotactic signalling molecules that are increasingly attracting attention in the study of tumourigenic mechanisms within malignant cells and the

*Correspondence: Dr DJj Waugh; E-mail: d.waugh@qub.ac.uk Received 19 August 2010; revised 16 November 2010; accepted 19 November 2010 tumour microenvironment. They are classified into four broad groups as follows: $\mathrm{C}, \mathrm{CC}, \mathrm{CXC}$ and $\mathrm{CX}_{3} \mathrm{C}$, on the basis of the position of their cysteine residues (Payne and Cornelius, 2002). The CXC-chemokines are subdivided further into ELR + and ELR-, depending on the amino-acid sequence before the first cysteine residue, and this confers angiogenic or angiostatic potential on these molecules (Strieter et al, 1995). The best characterized and prototypic CXC-chemokine is CXCL8, previously termed interleukin-8 (Rollins, 1997; Beck et al, 1999) and its biological effects are mediated through two G-protein-coupled receptors designated CXCR1 and CXCR2. A series of structurally related CXC-chemokines, including CXCL1, also bind selectively to the CXCR2 receptor (Ahuja and Murphy, 1996). Both CXCL1 and CXCL8 are pro-inflammatory mediators, functioning as chemotactic factors for neutrophils (Schroder et al, 1990a).

Multiple clinical studies implicate CXC-chemokines in the development and progression of CRC. For example, elevated tumour CXCL8 levels have been associated with increased tumour size, depth of infiltration, disease stage and liver metastasis, as well as a shorter overall survival time in CRC (Terada et al, 2005). Furthermore, the circulating level of CXCL8 in patients' serum is higher in more advanced disease stage and in the presence of bowel wall invasion, liver and/or lung metastasis (Ueda et al, 1994; Kaminska et al, 2005). The CXCL1 and its receptor CXCR2 are also 
widely reported to be elevated in CRC, the presence of which may facilitate CRC tumour progression (Erreni et al, 2009). However, none of these studies have specifically studied the expression profile of these chemokines and their receptors in stage II and III CRC patients who have had potentially curative resection. Thus, their potential as prognostic markers in this disease is unclear.

Chemokine signalling not only modulates the function of cancerous epithelial cells but also serves as an intermediary in the communication network between tumour cells and the surrounding stroma. CXC-chemokines have potent effects in recruiting immune cells to inflammatory sites and CXCL1 and CXCL8 are both associated with neutrophil recruitment and activation (Moser et al, 1990; Schroder et al, 1990a). Interestingly, assessment of the peritumoural inflammatory infiltrate has been shown to provide prognostic information in CRC (Roxburgh et al, 2009), raising interest in the study of their clinical implications in this and other solid tumours. Characterisation of CXC-chemokine expression in these tumour-infiltrating cells is however limited, whereas the clinical relevance of such expression remains uncertain.

Our study presents an immunohistochemical profile of the expression of CXC chemokines and their receptors in 254 stage II and III CRC tissues. The expression of CXCL1 and CXCL8 and their receptors CXCR1 and CXCR2 were evaluated within diseased epithelium and compared with adjacent normal epithelium in patient-matched samples. Additionally, CXCL8 expression was characterized throughout the immune infiltrate of the tumours. We report an increased expression of CXCL1, CXCR1 and CXCR2 in tumour, compared with the surrounding normal epithelium, providing evidence for enhanced autocrine CXC chemokine signalling in these cancer cells. Furthermore, we determine a range of CXCL8-positivity within the immune cell-infiltrate, with important clinical implications. Accordingly, the significance of epithelial tumour and tumour immune cell infiltrate expression of these markers is presented.

\section{MATERIALS AND METHODS}

\section{Patients and specimens}

Archived formalin-fixed and paraffin-embedded CRC tissue specimens of 254 patients with stage II and stage III CRC were retrieved for the study. The specimens were originally obtained during a randomised controlled phase III clinical trial comparing 16 weeks of De Gramont schedule FU/FA to observation alone in patients with stage II and III CRC (24). Patients were recruited from hospitals in Northern Ireland for this study between March 1994 and February 1997, in compliance with the tenets of the Declaration of Helsinki. The trial participants gave informed consent for the use of their tissue for further molecular biomarker studies, such as this, and ethical approval for this study was obtained from the local Ethics Committee.

\section{Tissue microarray construction}

The study was performed using archival, formalin-fixed paraffinembedded colon tumour samples. A total of 254 primary colon carcinoma cases were selected.

All formalin-fixed paraffin-embedded blocks were sectioned and stained with H\&E and graded by a pathologist (EWK) to confirm pathological stage and grade of the tumours, and the relevant tumour areas were marked and used as the donor cores for TMA construction. The construction was performed using the Beecher Instruments Tissue Microarrayer (Beecher Instruments, Silver Spring, MD, USA) (Kononen et al, 1998). Cores of $0.6 \mathrm{~mm}$ thickness were sampled in quadruplicate for each case.

\section{Immunohistochemistry}

Sections of $4 \mu \mathrm{m}$ thickness were cut from all TMAs for the purpose of immunohistochemistry.. Sections were immunostained with CXCL1 (R\&D Systems, Abingdon, UK, cat\# MAB275), CXCR1 (Biosource, Invitrogen, Carlsbad, CA, USA, cat\# AHR1522X), CXCR2 (Biosource, cat\# AHR1532X) and CXCL8 (Affinity Bioreagents, Golden, CO, USA, cat\# PA1-32883) on an automated platform (Bond system - Leica Microsystems, Bannockburn, IL, USA). Briefly, cut sections were subjected to on-board dewaxing and the following conditions: CXCL1 and CXCR2 - antigen retrieval in tri-sodium citrate buffer (Bond Epitope Retrieval 1 solution) for $10 \mathrm{~min}$ and 1:500 antibody dilution; CXCR1 antigen retrieval in EDTA buffer (Bond Epitope Retrieval 2 solution) for $20 \mathrm{~min}$ and 1:4000 antibody dilution; CXCL8 - no antigen retrieval and 1:500 antibody dilution. Detection of the antibody-antigen complex was achieved using a polymer-based kit (Bond Refine) with $\mathrm{DAB}$ as the chromogen. All sections were counterstained with haematoxylin. Negative controls were included for all sections by omitting the primary antibody and positive controls used included samples of tonsil and colonic adenocarcinoma.

\section{Immunohistochemical assessment}

Two reviewers who were blinded to the clinico-pathological details and clinical outcome of the cohort performed the immunohistochemical evaluation of the staining independently. Cores with at least $50 \%$ of the tissue preserved after sectioning were included in the study. The TMAs were stained for expression of the CXCchemokine receptors CXCR1 and CXCR2, and the ligands CXCL1 and CXCL8. Cytoplasmic epithelial staining of the tissue cores for CXCR1, CXCR2 and CXCL1 was detected and the degree of expression was recorded. This was determined by a combined score comprising the percentage of cells with staining (none $=0$; $<10 \%=1 ; 10-50 \%=2 ; 51-80 \%=3 ;>80 \%=4)$ and the intensity of the staining (none $=0$; weak $=1$; moderate $=2$; strong $=3$ ). The product of both values was described as the immunoreactivity score (IRS), and used for the final analysis (Remmele and Stegner, 1987); this method has been used in similar studies evaluating chemokine immunohistochemistry expression (Eck et al, 2003; Jiang et al, 2006). Colorectal cell epithelial CXCL8 staining was minimal and, therefore, formal evaluation was not performed.

Immunostaining of the surrounding infiltrating inflammatory cells was also observed, in relation to both malignant and normal tissue. Although the epithelial tissue had shown negligible staining for CXCL8, this infiltrate demonstrated clear differential staining, particularly within the tumour cores. Consequently we evaluated CXCL8 expression within these inflammatory cells, in order to explore the clinical implications of the differences in staining. Because of the limited size of the tissue cores and as the immunostaining in the inflammatory cells appeared homogenous, the scoring system used for the colorectal cells was deemed inappropriate for the infiltrate. Therefore, each core was denoted as either negative or positive for inflammatory cell CXCL8 expression. Only two of the cases evaluated had no visible inflammatory cells within their available cores; these were, therefore, regarded as negative. Cases with at least two positive staining cores were considered positive in the final analysis. There was strong correlation between the two scorers, and in discrepant cases, a consensus was reached after a joint review.

There was some sample loss through damage to the cores during TMA construction and sectioning, a well-recognised limitation of the procedure. Tissue damage rates ranging from 15 to $33 \%$ have been reported (Schraml et al, 1999; Mucci et al, 2000; Richter et al, 2000 ), and this study was able to recover $72 \%$ of cases for evaluation of the various markers, a proportion thus comparable to the literature. 


\section{Statistics}

Patient data had been collected via a centralised trial co-ordinating office during the period of the clinical study and stored electronically. Statistical analysis was performed via the SPSS 17 and SPSS 18 software packages (SPSS, Chicago, IL, USA). Differences between the mean IRS scores of the malignant and normal colorectal epithelium samples were compared using the paired Student's $t$-test. Correlation of CXC-chemokine and receptor expression was performed using Spearman rank correlation test. Association between the IRS scores and clinicopathological variables was assessed using $\chi^{2}$-test and Fisher's exact test as appropriate. Survival rates were compared using the Kaplan-Meier curves, and univariate survival analysis performed using the log-rank test. Multivariate survival analysis was performed through Cox regression analysis. A $P$-value of $<0.05$ was considered significant in all analyses performed.

\section{RESULTS}

\section{Clinical-pathological features}

The median age of the patients at the time of surgery was 64 years (range 35-80 years). Males $(n=149)$ and females $(n=105)$ were included in the study cohort and the median duration of follow up was 68 months (range 11-105 months). In total, 71 patients had rectal carcinoma, whereas 183 had colonic carcinoma. There was a predominance of patients with stage II disease among the patients (163 patients with stage II and 91 patients with stage III disease). Table 1 shows the clinico-pathological demographics of the patient cohort, along with the incidence of recurrence and survival status in the group.

Table I Clinicopathologic details of patient cohort

\begin{tabular}{|c|c|c|}
\hline & No. of patients $(n=254)$ & $\%$ \\
\hline \multicolumn{3}{|l|}{ Age (years) } \\
\hline Median & 64 & \\
\hline Range & $35-80$ & \\
\hline \multicolumn{3}{|l|}{ Gender } \\
\hline Male & 149 & 58.7 \\
\hline Female & 105 & 41.3 \\
\hline \multicolumn{3}{|l|}{ Tumour site } \\
\hline Colon & 183 & 72.0 \\
\hline Rectum & 71 & 28.0 \\
\hline \multicolumn{3}{|l|}{ UICC stage } \\
\hline Stage II & 163 & 64.2 \\
\hline Stage III & 91 & 35.6 \\
\hline \multicolumn{3}{|l|}{ Histological grade } \\
\hline 1 & 19 & 6.3 \\
\hline$\|$ & 197 & 77.6 \\
\hline III & 30 & 11.8 \\
\hline Not stated & 9 & 3.5 \\
\hline \multicolumn{3}{|c|}{ Received adjuvant treatment } \\
\hline Yes & 127 & 50.0 \\
\hline No & 127 & 50.0 \\
\hline \multicolumn{3}{|l|}{ Recurrence } \\
\hline Yes & 163 & 64.2 \\
\hline No & 91 & 34.8 \\
\hline \multicolumn{3}{|l|}{ Status at last review } \\
\hline Alive & 148 & 58.2 \\
\hline Dead-all causes & 106 & 41.8 \\
\hline Dead-from CRC & 85 & 33.5 \\
\hline
\end{tabular}

\section{Comparison of CXCR1, CXCR2, CXCL1 and CXCL8 expression within normal and malignant colorectal tissue}

The tissue specimens were evaluated for immunohistochemical expression of the CXC-chemokines CXCL1 and CXCL8 and their receptors CXCR1 and CXCR2 within the neoplastic and surrounding normal colorectal epithelium. Differences in the degree of expression of these markers within the cytoplasm of colorectal epithelial cells are illustrated in Figure 1A. The mean expression of CXCR1, CXCR2 and CXCL1 for each case was classified as absent or weak (IRS 0-3), moderate (IRS between three and nine) and strong (IRS nine and above) as has been previously described (Jiang et al, 2006). All the three markers showed predominantly weak to moderate expression within normal colorectal epithelium; conversely moderate to strong expression of each marker was exhibited by the colorectal tumour epithelium (Supplementary Table S1). Comparison of the mean IRS scores for CXCR1, CXCR2 and CXCL1 in malignant and non-malignant tissue confirmed higher expression of each chemokine marker in the tumour epithelium relative to adjacent normal colorectal tissue (Figure 2A). Additionally, correlation of the chemokine/receptor expression within the malignant epithelium demonstrated a modest, but statistically significant correlation between the expression of CXCL1 and its receptor CXCR2 in the cohort of patients $(r=0.263 ; P<0.001$; Supplementary Table S2).

There was no meaningful immunostaining for CXCL8 within the malignant or normal colorectal epithelium and this was, therefore, not included in the epithelial tissue analysis; however, we detected a significant and differential staining of CXCL8 within the infiltrating inflammatory cells in the tissue sections (Figure 1B). The majority of the tumour cores (65.4\%) expressed positive CXCL8 immunoreactivity within the tumour-associated inflammatory infiltrate. Conversely, $95.9 \%$ of the normal colorectal tissue cores had no detectable CXCL8 expression within their infiltrating inflammatory cells (Figure $2 \mathrm{~B}$ ).

\section{Association between CXCR1, CXCR2, CXCL1 and CXCL8 expression and clinico-pathological factors}

The association between CXCR1, CXCR2 and CXCL1 and CXCL8 expression in the tumour tissue and the various clinicopathological features of the study cohort is provided in Table 2. We observed a significantly higher level of CXCR1 epithelial expression in rectal cancer tissue compared with colon, with $18.6 \%$ of rectal tumour cases showing strong expression compared with $7.3 \%$ of colon cancer cases $(P=0.033)$. There was no significant difference in epithelial expression of the other markers between tumour sites. Although there was no statistically significant correlation between disease stage and neoplastic epithelial expression of the chemokine markers, a higher proportion of stage II patients had CXCL8-positive inflammatory cell infiltrate within tumour cores, compared with stage III patients $(P=0.031)$.

No association was found between tumour epithelial immunostaining for CXCR1, CXCR2 and CXCL1 or the tumour infiltrate expression of CXCL8 and age at diagnosis, disease stage, pathological grade or patient gender. Statistical analysis was performed using $\chi^{2}$-test or Fisher's exact test, as appropriate.

\section{Association with clinical outcome}

The primary objective of the clinical trial was to investigate the impact of 16 weeks of adjuvant 5FU chemotherapy on the clinical outcome of the patient cohort. In this analysis, there was no significant difference between the treatment and observation arms with respect to relapse-free and overall survival (Supplementary Figure S1). The median RFS and overall survival in each treatment arm were not reached at the time of analysis, and there was no 
A

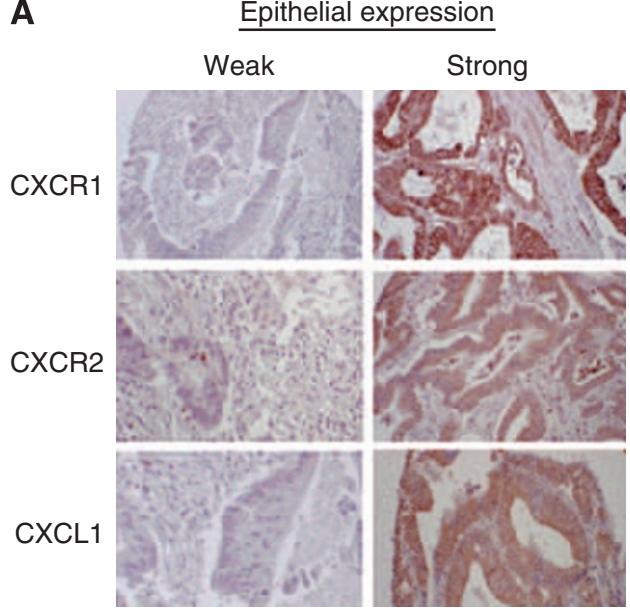

B Inflammatory cell expression

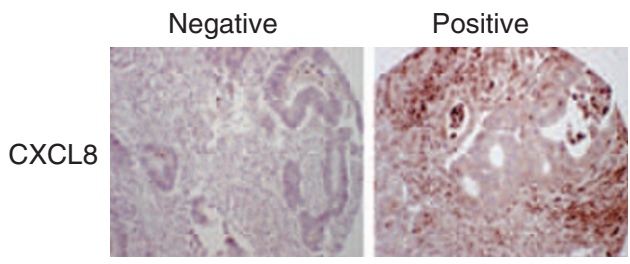

Figure I Immunohistochemical characterisation of CXC-chemokine and its receptor expression in colorectal tissue. (A) Representative high-powered images (magnification $\times 200$ ) illustrating weak (left panel) and strong (right panel) immunoreactivity to antibodies used to characterize the expression of CXCRI, CXCR2 and CXCLI in colorectal biopsy tissue. (B) Representative low-powered images showing differential expression of CXCL8 within the inflammatory cells surrounding the colorectal epithelial tissue.

A

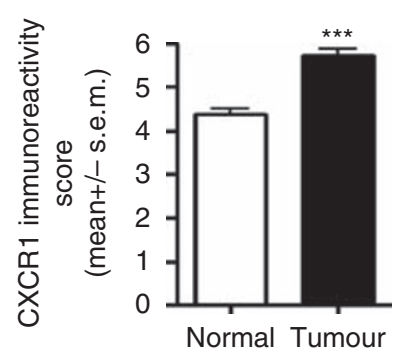

Epithelial tissue chemokine and receptor expression

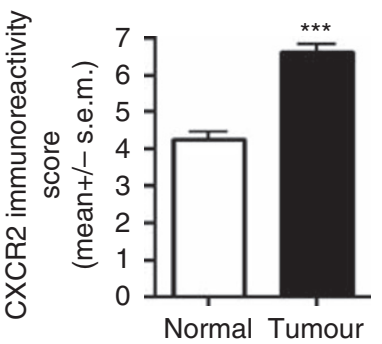

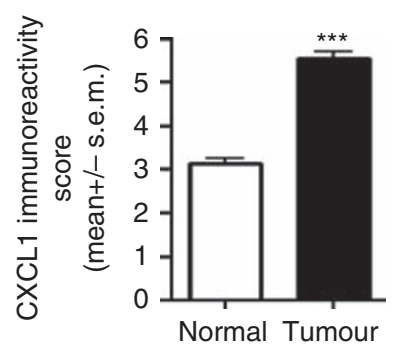

Normal Tumour

B Inflammatory infiltrate CXCL8 expression

Figure 2 Quantitative comparison of CXC-chemokine and its receptor expression in colorectal tissue. (A) Bar graphs presenting the relative immunoreactivity score calculated for CXCRI, CXCR2 and CXCLI in normal and malignant colorectal epithelial cells. The mean expression in tumor and normal tissues was compared using Student's t-test. Malignant tissue showed significantly higher levels of expression of all three markers in comparison to the surrounding normal tissue; *** $P<0.001$. (B) Bar graph illustrating the number of positive cases in which CXCL8 immunoreactivity was detected in the inflammatory cells surrounding the normal and malignant epithelial cells in the colorectal tissue. The majority of the cores with normal epithelium are absent for CXCL8 expression within the inflammatory infiltrate. In contrast, a greater number of cores with malignant epithelium show inflammatory cell CXCL8 positivity.

statistically significant difference between the Kaplan-Meier curves $(P=0.23$ and $P=0.38$, respectively, log-rank test). Additionally, in the current study the prognostic significance of CXC-chemokine ligand and receptor expression within CRC tissue was also determined, using univariate and multivariate survival analyses. Univariate analysis of the entire cohort (Table 3 ) showed that disease stage $(P<0.001)$, and interestingly, expression of CXCL8 within the tumour inflammatory infiltrate $(P<0.001)$ was the only significant factors impacting on recurrence-free survival (RFS). The Kaplan-Meier survival curve (Figure 3) demonstrated that patients with positive CXCL8 staining in this tumour infiltrate had a significantly improved RFS (median survival not reached) compared with patients with negative staining (median survival 69 months; 95\% CI: $37.7-100.3, P<0.001$ log-rank test). The degree of malignant epithelial tissue expression of the markers did not correlate with patient survival in the overall cohort, and co-expression did not improve their prognostic value (data not shown). However, further subgroup univariate analysis of stage III patients indicated a significant association between higher CXCL1 expression in the tumour samples and poorer RFS $(P=0.041)$. The Kaplan-Meier curve illustrates the poorer outcome of patients with strong CXCL1 immunostaining, relative to moderate or weak/absent expression (Supplementary Figure S2).

Multivariate analysis using Cox regression proportional hazard analysis confirmed disease stage and tumour infiltrate CXCL8 expression as independent predictors of RFS across the study cohort (Table 4). CXCL8-positivity in the tumour infiltrate was associated with a statistically significant reduction in the risk of disease recurrence (hazard ratio: $0.55, \mathrm{CI}: 0.36-0.85, P<0.001$ ).

\section{DISCUSSION}

In this study, we have conducted an extensive analysis of CXCchemokine and its receptor expression in CRC tissue using a tissue microarray comprising 254 stage II and stage III biopsies. Intermediate to strong expression of CXCL1, CXCR1 and CXCR2 was concurrently detected in the epithelium of stage II and stage III CRC tumours. In contrast, patient-matched normal epithelial tissue demonstrated predominantly weaker expression of these markers. Although CXCL1 expression has previously been detected in CRC epithelium (Cuenca et al, 1992; Baier et al, 2005; Wen et al, 
Table 2 Relationship between clinico-pathological factors and expression of CXC-chemokine biomarkers in the epithelial cells or immune-infiltrate of colorectal tissue

\begin{tabular}{|c|c|c|c|c|c|c|c|c|c|c|c|c|c|c|c|}
\hline & \multicolumn{4}{|c|}{$\begin{array}{c}\text { CXCRI expression } \\
(n=210)\end{array}$} & \multicolumn{4}{|c|}{$\begin{array}{c}\text { CXCR2 expression } \\
(n=189)\end{array}$} & \multicolumn{4}{|c|}{$\begin{array}{c}\text { CXCLI expression } \\
(n=213)\end{array}$} & \multicolumn{3}{|c|}{$\begin{array}{l}\text { Inflammatory cell CXCL8 } \\
\text { expression }(n=228)\end{array}$} \\
\hline & $\begin{array}{l}\text { Weak } \\
(n=28)\end{array}$ & $\begin{array}{c}\text { Moderate } \\
(n=160)\end{array}$ & $\begin{array}{l}\text { Strong } \\
(n=22)\end{array}$ & $P$-value & $\begin{array}{l}\text { Weak } \\
(n=18)\end{array}$ & $\begin{array}{c}\text { Moderate } \\
(n=120)\end{array}$ & $\begin{array}{l}\text { Strong } \\
(n=5 I)\end{array}$ & $P$-value & $\begin{array}{c}\text { Weak } \\
(n=30)\end{array}$ & $\begin{array}{c}\text { Moderate } \\
(n=162)\end{array}$ & $\begin{array}{l}\text { Strong } \\
(n=2 I)\end{array}$ & $P$-value & $\begin{array}{l}\text { Negative } \\
(n=79)\end{array}$ & $\begin{array}{l}\text { Positive } \\
(n=149)\end{array}$ & $P$-value \\
\hline \multicolumn{16}{|l|}{ Age } \\
\hline$<64$ & 14 (6.7\%) & $78(37.1 \%)$ & $10(4.8 \%)$ & & $8(4.2 \%)$ & 55 (29.1\%) & $28(\mid 4.8 \%)$ & & 17 (8.0\%) & 74 (34.7\%) & $13(6.1 \%)$ & & $39(17.1 \%)$ & $72(31.6 \%)$ & \\
\hline$>64$ & $14(6.7 \%)$ & $82(39.0 \%)$ & $12(5.7 \%)$ & 0.946 & $10(5.3 \%)$ & $65(34.4 \%)$ & $23(12.2 \%)$ & 0.525 & $13(6.1 \%)$ & $88(41.3 \%)$ & $8(3.8 \%)$ & 0.244 & $40(17.5 \%)$ & 77 (33.8\%) & 0.890 \\
\hline \multicolumn{16}{|l|}{ Gender } \\
\hline Male & 20 (9.5\%) & 92 (43.8\%) & $13(6.2 \%)$ & & $12(6.3 \%)$ & $71(37.6 \%)$ & 30 (I5.9\%) & & 17 (8.0\%) & 95 (44.6\%) & $12(5.6 \%)$ & & $43(18.9 \%)$ & 92 (40.4\%) & \\
\hline Female & $8(3.8 \%)$ & 68 (32.4\%) & $9(4.3 \%)$ & 0.383 & $6(3.2 \%)$ & 49 (25.9\%) & $21(11.1 \%)$ & 0.821 & $13(6.1 \%)$ & $67(31.5 \%)$ & 9 (4.2\%) & 0.975 & $36(15.8 \%)$ & $57(25.0 \%)$ & 0.322 \\
\hline \multicolumn{16}{|l|}{ Stage } \\
\hline$\|$ & $16(7.6 \%)$ & $103(49.0 \%)$ & $16(7.6 \%)$ & & I| (5.8\%) & $72(38.1 \%)$ & 39 (20.6\%) & & 18 (8.5\%) & 105 (49.3\%) & $14(6.6 \%)$ & & $43(18.9 \%)$ & $103(45.2 \%)$ & \\
\hline III & $12(5.7 \%)$ & $57(27.1 \%)$ & $6(2.9 \%)$ & 0.512 & $7(3.7 \%)$ & $48(25.4 \%)$ & $12(6.3 \%)$ & 0.114 & $12(5.6 \%)$ & 57 (26.8\%) & $7(3.3 \%)$ & 0.856 & $36(15.8 \%)$ & $46(20.2 \%)$ & 0.031 \\
\hline \multicolumn{16}{|l|}{ Site } \\
\hline Rectum & $5(2.4 \%)$ & 43 (20.5\%) & || (5.2\%) & & $6(3.2 \%)$ & $28(14.8 \%)$ & $12(6.3 \%)$ & & $8(3.8 \%)$ & 48 (22.5\%) & $2(0.9 \%)$ & & $16(7.0 \%)$ & 47 (20.6\%) & \\
\hline Colon & $23(11.0 \%)$ & 117 (55.7\%) & II (5.2\%) & 0.033 & $12(6.3 \%)$ & 92 (48.7\%) & 39 (20.6\%) & 0.646 & $22(10.3 \%)$ & 114 (53.5\%) & $19(8.9 \%)$ & 0.150 & $63(27.6 \%)$ & $102(44.7 \%)$ & 0.087 \\
\hline \multicolumn{16}{|c|}{ Received chemotherapy } \\
\hline No & $15(7.1 \%)$ & $75(35.7 \%)$ & $13(6.2 \%)$ & & $8(4.2 \%)$ & $53(28.0 \%)$ & $24(12.7 \%)$ & & $15(7.0 \%)$ & $81(38.0 \%)$ & II (5.2\%) & & $46(20.2 \%)$ & $71(31.1 \%)$ & \\
\hline Yes & $13(6.2 \%)$ & $85(40.5 \%)$ & $9(4.3 \%)$ & 0.492 & $10(5.3 \%)$ & $67(35.4 \%)$ & $27(14.3 \%)$ & 0.940 & $15(7.0 \%)$ & $81(38.0 \%)$ & $10(4.7 \%)$ & 0.979 & $33(14.5 \%)$ & $78(34.2 \%)$ & 0.164 \\
\hline
\end{tabular}

Values shown in italic are not significant.

Table 3 Univariate survival analysis for epithelial CXC-chemokine expression

\begin{tabular}{|c|c|c|c|c|c|c|c|c|c|c|c|c|}
\hline & \multicolumn{4}{|c|}{ All patients $(n=254)$} & \multicolumn{4}{|c|}{ Stage II patients $(n=163)$} & \multicolumn{4}{|c|}{ Stage III patients $(n=91)$} \\
\hline & \multicolumn{2}{|c|}{$\begin{array}{l}\text { Recurrence-free } \\
\text { survival }\end{array}$} & \multicolumn{2}{|c|}{$\begin{array}{l}\text { Overall } \\
\text { survival }\end{array}$} & \multicolumn{2}{|c|}{$\begin{array}{l}\text { Recurrence-free } \\
\text { survival }\end{array}$} & \multicolumn{2}{|c|}{$\begin{array}{l}\text { Overall } \\
\text { survival }\end{array}$} & \multicolumn{2}{|c|}{$\begin{array}{c}\text { Recurrence-free } \\
\text { survival }\end{array}$} & \multicolumn{2}{|c|}{$\begin{array}{l}\text { Overall } \\
\text { survival }\end{array}$} \\
\hline & $\begin{array}{l}\text { Recurrences/ } \\
\text { no. of patients }\end{array}$ & $\begin{array}{l}\text { log-rank } \\
(P)\end{array}$ & $\begin{array}{c}\text { Deaths/ } \\
\text { no. of } \\
\text { patients }\end{array}$ & $\begin{array}{l}\text { log-rank } \\
(P)\end{array}$ & $\begin{array}{l}\text { Recurrences/ } \\
\text { no. of patients }\end{array}$ & $\begin{array}{l}\text { log-rank } \\
(P)\end{array}$ & $\begin{array}{c}\text { Deaths/ } \\
\text { no. of } \\
\text { patients }\end{array}$ & $\begin{array}{l}\text { log-rank } \\
(P)\end{array}$ & $\begin{array}{l}\text { Recurrences/ } \\
\text { no. of patients }\end{array}$ & $\begin{array}{l}\text { log-rank } \\
(P)\end{array}$ & $\begin{array}{c}\text { Deaths/ } \\
\text { no. of } \\
\text { patients }\end{array}$ & $\begin{array}{c}\text { log-rank } \\
(P)\end{array}$ \\
\hline \multicolumn{13}{|l|}{ Tumour stage } \\
\hline$\|$ & $40 / 163$ & & $51 / 163$ & & & & & & & & & \\
\hline III & $5|/ 9|$ & $<0.001$ & $55 / 91$ & $<0.001$ & & & & & & & & \\
\hline \multicolumn{13}{|c|}{ Tumour epithelial CXCRI } \\
\hline Absent/weak & $7 / 28$ & & $9 / 28$ & & $6 / 19$ & & $7 / 19$ & & $1 / 9$ & & $2 / 9$ & \\
\hline Moderate & $63 / 160$ & 0.379 & $69 / 160$ & 0.586 & $59 / 103$ & 0.156 & $65 / 103$ & 0.146 & $4 / 57$ & 0.675 & $4 / 57$ & 0.106 \\
\hline Strong & $10 / 22$ & & $11 / 22$ & & $10 / 14$ & & $11 / 14$ & & $0 / 8$ & & $0 / 8$ & \\
\hline \multicolumn{13}{|c|}{ Tumour epithelial CXCR2 } \\
\hline Absent/weak & $8 / 18$ & & $9 / 18$ & & $8 / 13$ & & $9 / 13$ & & $0 / 5$ & & $0 / 5$ & \\
\hline Moderate & $45 / 120$ & 0.748 & $47 / 120$ & 0.482 & $40 / 74$ & 0.879 & $42 / 74$ & 0.880 & $5 / 46$ & 0.314 & $5 / 46$ & 0.698 \\
\hline Strong & $|8 / 5|$ & & $25 / 51$ & & $18 / 36$ & & $23 / 36$ & & $0 / 15$ & & $2 / 15$ & \\
\hline \multicolumn{13}{|c|}{ Tumour epithelial CXCLI } \\
\hline Absent/weak & $9 / 30$ & & $9 / 30$ & & $8 / 14$ & & $9 / 14$ & & $1 / 16$ & & $0 / 16$ & \\
\hline Moderate & $63 / 162$ & 0.546 & $71 / 162$ & 0.409 & $61 / 107$ & 0.585 & $66 / 107$ & 0.628 & $2 / 55$ & 0.041 & $5 / 55$ & 0.061 \\
\hline Strong & $8 / 21$ & & $9 / 21$ & & $6 / 14$ & & $7 / 14$ & & $2 / 7$ & & $2 / 7$ & \\
\hline \multicolumn{13}{|c|}{ Tumour inflammatory infiltrate CXCL8 } \\
\hline Negative & $42 / 79$ & & $39 / 79$ & & $38 / 50$ & & $36 / 50$ & & $4 / 29$ & & $3 / 29$ & \\
\hline Positive & $42 / 149$ & $<0.001$ & $58 / 149$ & 0.150 & $41 / 99$ & $<0.001$ & $54 / 99$ & 0.029 & $1 / 50$ & 0.040 & $4 / 50$ & 0.806 \\
\hline
\end{tabular}

Values shown in italic are not significant.

2006), our analysis showed an additional correlation between CXCL1 and the expression of its biological target, the CXCR2 receptor within the tumour samples $(P<0.001)$. Therefore, our study is the first to indicate concurrent ligand and receptor expression in CRC tissue, suggesting a continuous autocrine CXC-chemokine signalling stimulus within these cells.

It is noteworthy that no significant CXCL8 immunoreactivity was detected in the CRC tissue, despite using similar approaches that were previously successful in assessing CXCL8 expression in prostate cancer epithelium (Murphy et al, 2005). Previous studies that have characterized CXCL8 expression in CRC tissue have often been conducted in a more advanced disease stage and used techniques other than immunohistochemistry (Ueda et al, 1994; Chung and Chang, 2003; Csiszar et al, 2004; Erreni et al, 2009), however, almost two-thirds of our cohort comprised stage II CRC. Therefore, it is conceivable that the good prognosis of this patient selection may explain the absence of CXCL8 immunoreactivity in the epithelial cells. Instead, we postulate that the expression of CXCL8 may become detectable and especially significant in a more advanced disease stage, indicative of the tumour-promoting effects 
Inflammatory infiltrate CXCL8 expression and relapse-free survival

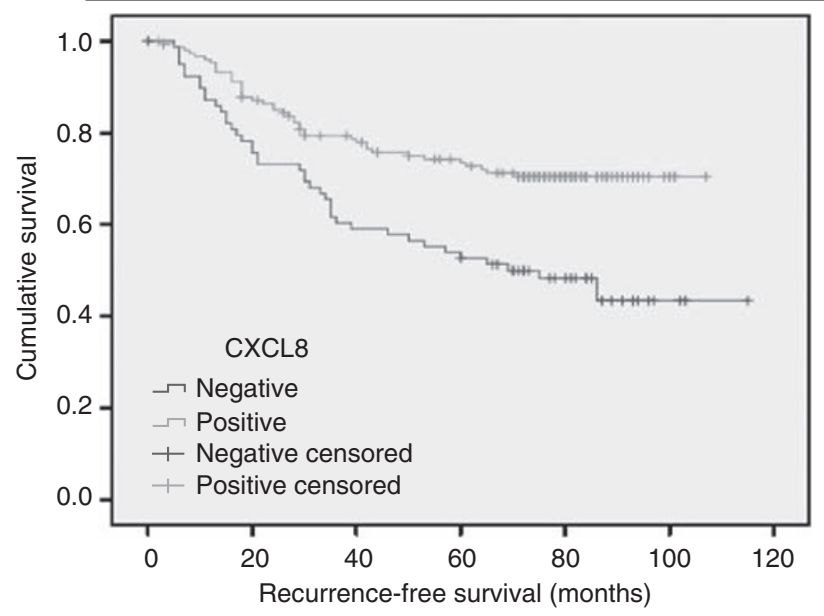

Figure 3 Relapse-free survival of stage II and III CRC patients, based on CXCL8 expression within the tumour inflammatory infiltrate. KaplanMeier curve representing the recurrence-free survival of stage II and stage III colorectal cancer patients. Samples were stratified on the basis of either positive or negative CXCL8 immunoreactivity within the infiltrating immune cells surrounding the tumor epithelium. Patients with a CXCL8 positive infiltrate were shown to have an increased relapse-free survival with the median interval not being reached. In contrast, patients with no CXCL8 immunoreactivity had a median survival of 69 months $(P<0.01$; log-ranks test).

Table 4 Multivariate survival analysis for epithelial- and immune infiltratelocalized CXC-chemokine expression

\begin{tabular}{|c|c|c|c|c|}
\hline & \multicolumn{2}{|c|}{ Recurrence-free survival } & \multicolumn{2}{|c|}{ Overall survival } \\
\hline & Hazard ratio & $95 \% \mathrm{Cl}(P)$ & Hazard ratio & $95 \% \mathrm{Cl}(P)$ \\
\hline \multicolumn{5}{|l|}{ UICC stage } \\
\hline Stage II & I & $1.92-4.62$ & । & $1.60-3.92$ \\
\hline Stage III & 2.98 & $(P<0.00 I)$ & 2.50 & $(P<0.001)$ \\
\hline \multicolumn{5}{|c|}{ Inflammatory infiltrate CXCL8 } \\
\hline Negative & | & $0.36-0.85$ & । & $0.462-1.147$ \\
\hline Positive & 0.55 & $(P=0.007)$ & 0.728 & $(P=0.17 \mid)$ \\
\hline
\end{tabular}

of the chemokine. Irrespective, the characterisation of CXCL1 and CXCR2 expression in the tumour epithelium provides a functional compensation for the absence of CXCL8. Alternative and more quantitative methods of detection of CXCL8, such assessment of gene expression by PCR, may be of added utility to further investigate these and other chemokines and receptors.

Although extensive analysis was performed, we found no association between CXCR1 and CXCR2 expression and patient outcome in the overall cohort (stage II and stage III tumours). However, a univariate analysis did identify a significant association between elevated CXCL1 expression and poorer relapse-free survival in stage III CRC patients. $(P=0.04)$. Although not addressed in this study, de-regulated CXCL1 and CXCL8 signalling has been associated with increased cell proliferation and migratory responses in CRC cells (Brew et al, 2000; Itoh et al, 2005). Increased secretion of CXCL1 and CXCL8 from tumour epithelium has also been reported to induce angiogenesis in gastro-intestinal cancers (Heidemann et al, 2003; Wang et al, 2006; Matsuo et al, 2009). Furthermore, in Hodgkins' disease, CXCL1 chemoattraction of inflammatory cells contributes to a complex tumour-host cellular interplay that can result in suppression of cell-mediated cellular immune response and consequently, tumour progression (Skinnider and Mak, 2002). Therefore, it is conceivable that, these individual or combined functions may contribute to the association of CXCL1 expression with an unfavourable outcome in stage III CRC. Understanding the impact of these potential roles of CXCL1 to adverse prognosis merits further studies in CRC collections that include a greater overall number of stage III and/or stage IV tumours.

The previous observation of stage dependence in relation to the prognostic potential of a specific CXC-chemokine's expression raises several important considerations. The impact of CXCchemokine signalling on clinical outcome is likely to be influenced by numerous factors, including the genetic background of the tumour. For example, increased CXCR2 signalling reportedly underpins oncogenic Ras-induced senescence in p53 wild-type tumour cells (Acosta et al, 2008), but the effects of oncogenic Ras-induced CXC-chemokine signalling may have different effects, for example, in cells harbouring abnormal p53 function. Furthermore, we have shown that stress-induced expression of CXCchemokines and the magnitude of their signalling effects are more significant in amplitude and duration in PTEN-deficient prostate cancer cells compared with the PTEN-wild-type counterparts (Maxwell and Waugh, unpublished observations). Although unconfirmed, it is plausible that our patient cohort with stage III disease may have different underlying genetic defects than stage II patients; indeed, this concept is currently under investigation through a number of clinical studies (Tejpar et al, 2010). Under these circumstances, the increase in CXCL1/CXCR2 signalling may underpin a more adverse clinical impact. More studies in larger cohorts, together with a comprehensive characterisation of the genetic constitution within the tumours would be useful to further explore the merits of our observation.

As alluded to, CXC-chemokine expression within the surrounding tumour microenvironment, distinct from the cancer cell epithelial expression, has been an additional area of investigation. Perhaps the most intriguing observation in this study is the identified impact of peritumoural inflammatory cell CXCL8 expression upon patient outcome. Indeed, positive CXCL8 inflammatory infiltrate expression resulted in enhanced relapsefree survival relative to negative expression, with a hazard ratio of 0.55 . This is a considerable improvement in the outcome of a group of patients with an already favourable prognosis (two-thirds stage II disease), and was independent of disease stage on multivariate analysis. Chemokines such as CXCL8 are known to exert potent chemotactic influences on a range of inflammatory cells, such as T cells, neutrophils and basophils (Oppenheim et al, 1991), the full implications of which are yet to be fully elucidated and may be relevant to our findings. For example, the prognostic significance of tumour-associated inflammatory cells in gastrooesophageal cancer is conflicting, with the role of infiltrating macrophages and lymphocytes being reported as both favourable and adverse in contradictory reports (Ma et al, 1999; Ohno et al, 2003; Koide et al, 2004; Deans et al, 2006). However, in general the presence of increased tumour-related cellular infiltrate has been associated with improved survival in CRC (Jass, 1986; Nielsen et al, 1999; Canna et al, 2005); nevertheless, there has been limited characterisation of the expression of pro-inflammatory mediators, including CXC-chemokines within these cells. Our study addressed this question in relation to CXCL8 expression, and provides novel clinical evidence linking such expression specifically within the tumour infiltrate and within these well-defined disease stages to improved patient outcome.

The good prognostic effect conferred by the infiltrate's CXCL8 positivity most likely reflects the immune functions of this chemokine and the anti-tumour role of the inflammatory cells. Although CXCL8 is recognised for its ability to recruit immune cells, the chemokine also induces neutrophil activation promoting the respiratory burst characteristic of these cells. This triggers the 
release of mediators into the tumour microenvironment, which can facilitate antitumour cytotoxicity (Schroder et al, 1990b). Thus, the CXCL8 immunoreactivity detected within the tumour infiltrate may correlate with increased activity of the immune cells. This scenario has been predicted from an experimental model of ovarian cancer in which elevated intra-tumoural CXCL8 expression correlated with an increased infiltration of neutrophils and macrophages and a decreased tumourigenicity (Lee et al, 2000). This fascinating observation, therefore, justifies the execution of larger cohort studies to validate our findings. Characterisation of the underlying mechanisms that could explain the observed survival benefit of CXCL8 in this context will also be necessary.
In conclusion, this study demonstrates CXC-chemokine and its receptor expression within CRC tissue. Expression of CXCL1 is associated with a poor prognosis in stage III CRC. Conversely, increased expression of CXCL8 in the inflammatory cell infiltrate of the tumour tissue is associated with a favourable prognosis in this cohort of stage II and stage III CRC tissues. Thus, we demonstrate the potentially distinct effects of chemokine expression and signalling on tumour progression and clinical prognosis within different compartments of the tumour microenvironment.

Supplementary Information accompanies the paper on British Journal of Cancer website (http://www.nature.com/bjc)

\section{REFERENCES}

Acosta JC, O'Loghlen A, Banito A, Guijarro MV, Augert A, Raguz S, Fumagalli M, Da Costa M, Brown C, Popov N, Takatsu Y, Melamed J, d'Adda di Fagagna F, Bernard D, Hernando E, Gil J (2008) Chemokine signaling via the CXCR2 receptor reinforces senescence. Cell 133: $1006-1018$

Ahuja SK, Murphy PM (1996) The CXC chemokines growth-regulated oncogene (GRO) alpha, GRObeta, GROgamma, neutrophil-activating peptide-2, and epithelial cell-derived neutrophil-activating peptide-78 are potent agonists for the type B, but not the type A, human interleukin-8 receptor. J Biol Chem 271: 20545-20550

Allegra CJ, Paik S, Colangelo LH, Parr AL, Kirsch I, Kim G, Klein P, Johnston PG, Wolmark N, Wieand HS (2003) Prognostic value of thymidylate synthase, Ki-67, and p53 in patients with Dukes' B and C colon cancer: a National Cancer Institute-National Surgical Adjuvant Breast and Bowel Project collaborative study. J Clin Oncol 21: 241-250

Baier PK, Eggstein S, Wolff-Vorbeck G, Baumgartner U, Hopt UT (2005) Chemokines in human colorectal carcinoma. Anticancer Res 25: $3581-3584$

Beck GC, Yard BA, Breedijk AJ, Van Ackern K, Van Der Woude FJ (1999) Release of CXC-chemokines by human lung microvascular endothelial cells (LMVEC) compared with macrovascular umbilical vein endothelial cells. Clin Exp Immunol 118: 298-303

Brew R, Erikson JS, West DC, Kinsella AR, Slavin J, Christmas SE (2000) Interleukin-8 as an autocrine growth factor for human colon carcinoma cells in vitro. Cytokine 12: 78-85

Canna K, McArdle PA, McMillan DC, McNicol AM, Smith GW, McKee RF, McArdle CS (2005) The relationship between tumour T-lymphocyte infiltration, the systemic inflammatory response and survival in patients undergoing curative resection for colorectal cancer. Br J Cancer 92: 651 - 654

Chung YC, Chang YF (2003) Significance of inflammatory cytokines in the progression of colorectal cancer. Hepatogastroenterology 50: 1910-1913

Csiszar A, Szentes T, Haraszti B, Balazs A, Petranyi GG, Pocsik E (2004) The pattern of cytokine gene expression in human colorectal carcinoma. Pathol Oncol Res 10: 109-116

Cuenca RE, Azizkhan RG, Haskill S (1992) Characterization of GRO alpha, beta and gamma expression in human colonic tumours: potential significance of cytokine involvement. Surg Oncol 1: 323-329

Deans DA, Wigmore SJ, Gilmour H, Paterson-Brown S, Ross JA, Fearon KC (2006) Elevated tumour interleukin-1beta is associated with systemic inflammation: a marker of reduced survival in gastro-oesophageal cancer. Br J Cancer 95: $1568-1575$

Eck M, Schmausser B, Scheller K, Brandlein S, Muller-Hermelink HK (2003) Pleiotropic effects of CXC chemokines in gastric carcinoma: differences in CXCL8 and CXCL1 expression between diffuse and intestinal types of gastric carcinoma. Clin Exp Immunol 134: 508-515

Erreni M, Bianchi P, Laghi L, Mirolo M, Fabbri M, Locati M, Mantovani A, Allavena P (2009) Expression of chemokines and chemokine receptors in human colon cancer. Methods Enzymol 460: 105-121

Ferlay J, Autier P, Boniol M, Heanue M, Colombet M, Boyle P (2007) Estimates of the cancer incidence and mortality in Europe in 2006. Ann Oncol 18: $581-592$

Heidemann J, Ogawa H, Dwinell MB, Rafiee P, Maaser C, Gockel HR, Otterson MF, Ota DM, Lugering N, Domschke W, Binion DG (2003) Angiogenic effects of interleukin 8 (CXCL8) in human intestinal microvascular endothelial cells are mediated by CXCR2. J Biol Chem 278: $8508-8515$

Itoh Y, Joh T, Tanida S, Sasaki M, Kataoka H, Itoh K, Oshima T, Ogasawara N, Togawa S, Wada T, Kubota H, Mori Y, Ohara H, Nomura T, Higashiyama S, Itoh M (2005) IL-8 promotes cell proliferation and migration through metalloproteinase-cleavage proHB-EGF in human colon carcinoma cells. Cytokine 29: $275-282$

Jass JR (1986) Lymphocytic infiltration and survival in rectal cancer. J Clin Pathol 39: $585-589$

Jiang YP, Wu XH, Shi B, Wu WX, Yin GR (2006) Expression of chemokine CXCL12 and its receptor CXCR4 in human epithelial ovarian cancer: an independent prognostic factor for tumor progression. Gynecol Oncol 103: $226-233$

Kaminska J, Nowacki MP, Kowalska M, Rysinska A, Chwalinski M, Fuksiewicz M, Michalski W, Chechlinska M (2005) Clinical significance of serum cytokine measurements in untreated colorectal cancer patients: soluble tumor necrosis factor receptor type I - an independent prognostic factor. Tumour Biol 26: 186-194

Koide N, Nishio A, Sato T, Sugiyama A, Miyagawa S (2004) Significance of macrophage chemoattractant protein-1 expression and macrophage infiltration in squamous cell carcinoma of the esophagus. $\mathrm{Am} J$ Gastroenterol 99: 1667-1674

Kononen J, Bubendorf L, Kallioniemi A, Barlund M, Schraml P, Leighton S, Torhorst J, Mihatsch MJ, Sauter G, Kallioniemi OP (1998) Tissue microarrays for high-throughput molecular profiling of tumor specimens. Nat Med 4: 844-847

Lee LF, Hellendall RP, Wang Y, Haskill JS, Mukaida N, Matsushima K, Ting JP (2000) IL-8 reduced tumorigenicity of human ovarian cancer in vivo due to neutrophil infiltration. J Immunol 164: 2769-2775

Ma Y, Xian M, Li J, Kawabata T, Okada S (1999) Interrelations of clinicopathological variables, local immune response and prognosis in esophageal squamous cell carcinoma. APMIS 107: 514-522

Matsuo Y, Ochi N, Sawai H, Yasuda A, Takahashi H, Funahashi H, Takeyama H, Tong Z, Guha S (2009) CXCL8/IL-8 and CXCL12/ SDF-1alpha co-operatively promote invasiveness and angiogenesis in pancreatic cancer. Int J Cancer 124: 853-861

McArdle CS, Hole DJ (2002) Outcome following surgery for colorectal cancer: analysis by hospital after adjustment for case-mix and deprivation. Br J Cancer 86: $331-335$

Moser B, Clark-Lewis I, Zwahlen R, Baggiolini M (1990) Neutrophilactivating properties of the melanoma growth-stimulatory activity. J Exp Med 171: $1797-1802$

Mucci NR, Akdas G, Manely S, Rubin MA (2000) Neuroendocrine expression in metastatic prostate cancer: evaluation of high throughput tissue microarrays to detect heterogeneous protein expression. Hum Pathol 31: 406-414

Murphy C, McGurk M, Pettigrew J, Santinelli A, Mazzucchelli R, Johnston PG, Montironi R, Waugh DJ (2005) Nonapical and cytoplasmic expression of interleukin-8, CXCR1, and CXCR2 correlates with cell proliferation and microvessel density in prostate cancer. Clin Cancer Res 11: $4117-4127$

Nielsen HJ, Hansen U, Christensen IJ, Reimert CM, Brunner N, Moesgaard F (1999) Independent prognostic value of eosinophil and mast cell infiltration in colorectal cancer tissue. J Pathol 189: 487-495 
Ohno S, Inagawa H, Dhar DK, Fujii T, Ueda S, Tachibana M, Suzuki N, Inoue M, Soma G, Nagasue N (2003) The degree of macrophage infiltration into the cancer cell nest is a significant predictor of survival in gastric cancer patients. Anticancer Res 23: 5015-5022

Oppenheim JJ, Zachariae CO, Mukaida N, Matsushima K (1991) Properties of the novel proinflammatory supergene 'intercrine' cytokine family. Annu Rev Immunol 9: 617-648

Parkin DM, Bray F, Ferlay J, Pisani P (2005) Global cancer statistics, 2002. CA Cancer J Clin 55: 74-108

Payne AS, Cornelius LA (2002) The role of chemokines in melanoma tumor growth and metastasis. J Invest Dermatol 118: 915-922

Remmele W, Stegner HE (1987) Recommendation for uniform definition of an immunoreactive score (IRS) for immunohistochemical estrogen receptor detection (ER-ICA) in breast cancer tissue. Pathologe 8: $138-140$

Richter J, Wagner U, Kononen J, Fijan A, Bruderer J, Schmid U, Ackermann D, Maurer R, Alund G, Knonagel H, Rist M, Wilber K, Anabitarte M, Hering F, Hardmeier T, Schonenberger A, Flury R, Jager P, Fehr JL, Schraml P, Moch H, Mihatsch MJ, Gasser T, Kallioniemi OP, Sauter G (2000) High-throughput tissue microarray analysis of cyclin $\mathrm{E}$ gene amplification and overexpression in urinary bladder cancer. Am J Pathol 157: $787-794$

Rollins BJ (1997) Chemokines. Blood 90: 909-928

Roxburgh CS, Salmond JM, Horgan PG, Oien KA, McMillan DC (2009) Tumour inflammatory infiltrate predicts survival following curative resection for node-negative colorectal cancer. Eur J Cancer 45: $2138-2145$

Schraml P, Kononen J, Bubendorf L, Moch H, Bissig H, Nocito A, Mihatsch MJ, Kallioniemi OP, Sauter G (1999) Tissue microarrays for gene amplification surveys in many different tumor types. Clin Cancer Res 5: $1966-1975$

Schroder JM, Persoon NL, Christophers E (1990a) Lipopolysaccharidestimulated human monocytes secrete, apart from neutrophil-activating peptide 1/interleukin 8 , a second neutrophil-activating protein. NH2-terminal amino acid sequence identity with melanoma growth stimulatory activity. $J$ Exp Med 171: $1091-1100$

Schroder JM, Sticherling M, Henneicke HH, Preissner WC, Christophers E (1990b) IL-1 alpha or tumor necrosis factor-alpha stimulate release of three NAP-1/IL-8-related neutrophil chemotactic proteins in human dermal fibroblasts. J Immunol 144: 2223-2232

Skinnider BF, Mak TW (2002) The role of cytokines in classical Hodgkin lymphoma. Blood 99: 4283-4297

Strieter RM, Polverini PJ, Kunkel SL, Arenberg DA, Burdick MD, Kasper J, Dzuiba J, Van Damme J, Walz A, Marriott D (1995) The functional role of the ELR motif in CXC chemokine-mediated angiogenesis. J Biol Chem 270: $27348-27357$

Tejpar S, Bertagnolli M, Bosman F, Lenz HJ, Garraway L, Waldman F, Warren R, Bild A, Collins-Brennan D, Hahn H, Harkin DP, Kennedy R, Ilyas M, Morreau H, Proutski V, Swanton C, Tomlinson I, Delorenzi M, Fiocca R, Van Cutsem E, Roth A (2010) Prognostic and predictive biomarkers in resected colon cancer: current status and future perspectives for integrating genomics into biomarker discovery. Oncologist 15: 390 - 404

Terada H, Urano T, Konno H (2005) Association of interleukin-8 and plasminogen activator system in the progression of colorectal cancer. Eur Surg Res 37: 166-172

Ueda T, Shimada E, Urakawa T (1994) Serum levels of cytokines in patients with colorectal cancer: possible involvement of interleukin-6 and interleukin-8 in hematogenous metastasis. J Gastroenterol 29: 423-429

Wang D, Wang H, Brown J, Daikoku T, Ning W, Shi Q, Richmond A, Strieter R, Dey SK, DuBois RN (2006) CXCL1 induced by prostaglandin E2 promotes angiogenesis in colorectal cancer. J Exp Med 203: 941 - 951 Wen Y, Giardina SF, Hamming D, Greenman J, Zachariah E, Bacolod MD, Liu H, Shia J, Amenta PS, Barany F, Paty P, Gerald W, Notterman D (2006) GROalpha is highly expressed in adenocarcinoma of the colon and down-regulates fibulin-1. Clin Cancer Res 12: 5951-5959 